\title{
Two-Way Shape Memory Effect Induced by Bending Deformation in Ductile $\mathbf{C u}-\mathbf{A l}-\mathbf{M n}$ Alloys
}

\author{
Toshihiro Omori *, Jijie Wang*, Yuji Sutou, Ryosuke Kainuma and Kiyohito Ishida \\ Department of Materials Science, Graduate School of Engineering, Tohoku University, Sendai 980-8579, Japan
}

\begin{abstract}
Martensitic transformation temperatures and the two-way shape memory effect (TWME) in ductile $\mathrm{Cu}-\mathrm{Al}-\mathrm{Mn}$ alloys deformed at room temperature were investigated using differential scanning calorimetry (DSC) and the bending test. The $M_{s}$ and $A_{f}$ temperatures were found to increase slightly with increasing degree of pre-deformation, while the $M_{f}$ and $A_{s}$ temperatures decreased. The TWME is strongly influenced by the $M_{s}$ temperature and the grain size of the specimens, i.e., the highest degree of TWME is always obtained in the specimens with $M_{s} \approx-100^{\circ} \mathrm{C}$ and the TWME increases with increasing ratio of grain size to specimen width, where the maximum value of TWME $=3.2 \%$ was obtained in the present study. In situ observation of the surface relief at several temperatures on the deformed specimens was also performed and it was found that some restricted martensite variants grow and shrink with temperature change without the typical self-accommodation microstructure in the specimens with large TWME.
\end{abstract}

(Received January 7, 2002; Accepted May 7, 2002)

Keywords: copper-aluminum-manganese, martensitic transformation, two-way shape memory effect (TWME), grain size

\section{Introduction}

$\mathrm{Cu}$-base shape memory (SM) alloys are commercially attractive because of their low cost and high electrical and thermal conductivities compared with Ti-Ni-base alloys, which have been extensively investigated in SM applications. These highly ordered $\mathrm{Cu}$-base alloys with a polycrystalline structure, however, are not amenable to cold-working due to the high degree of elastic anisotropy of the parent phase and their coarse grain structure. Recently, the present authors have reported that the $\mathrm{Cu}-\mathrm{Al}-\mathrm{Mn}$ alloys with a low $\mathrm{Al}$ content below 18 at $\%$ exhibit a good ductility due to the low degree of order in the Heusler $\left(\mathrm{L} 2{ }_{1}\right)$ phase which is transformed to the $18 \mathrm{R}$ martensite phase without associated loss of the SM properties. $^{1-3)}$

The two-way shape memory effect (TWME) associated with the forward and reverse transformations of martensite is a phenomenon in which the reversible and spontaneous shape change during heating and cooling occurs without any external stress. It has been believed that dislocation arrays, ${ }^{4-6)}$ retained martensite ${ }^{4,7)}$ and residual stress fields ${ }^{8,9)}$ are necessary to obtain the TWME. Although this effect can be obtained by various processes such as superelastic (SE) or shape memory effect (SME) training, thermomechanical training, aging under external stress, etc., one of the simplest processes may be a single high deformation method applied in the austenite or martensite state. Although conventional $\mathrm{Cu}-$ base SM alloys are characterized by low cold fabricability, the ductile $\mathrm{Cu}-\mathrm{Al}-\mathrm{Mn}$ alloy possesses an excellent ductility with more than $60 \%$ cold-workability even in the $\beta$ single-phase, and it can be expected to show the good TWME property by the heavy deformation method.

In this paper, the TWME induced by single high deformation in the ductile $\mathrm{Cu}-\mathrm{Al}-\mathrm{Mn}$ alloy is presented in relation to the degree of deformation, the martensitic transformation starting $\left(M_{S}\right)$ temperature and the grain size of the specimens. The effects of deformation on the martensitic transformation

${ }^{*}$ Graduate Student, Tohoku University. temperatures are also examined.

\section{Experimental Procedures}

The $\mathrm{Cu}-\mathrm{Al}-\mathrm{Mn}$ ternary alloys listed in Table 1 were prepared by induction melting under an argon atmosphere. Sheet specimens were obtained by hot-rolling the cast alloy at $800^{\circ} \mathrm{C}$, followed by further cold-rolling. The specimens were annealed at $900^{\circ} \mathrm{C}$ for 25 seconds or 5 minutes, followed by quenching in water, and then aged at $200^{\circ} \mathrm{C}$ for 15 minutes to stabilize the $M_{s}$ temperature. The grain size was controlled by annealing time. The $\mathrm{Cu}_{69.5} \mathrm{Zn}_{24.5} \mathrm{Al}_{6}$ sheet specimens of $t=0.5 \mathrm{~mm}$ thickness obtained by hot-rolling were heat-treated at $900^{\circ} \mathrm{C}$ for 5 minutes, followed by quenching in water, and then aged at $120^{\circ} \mathrm{C}$ for 5 minutes. The mean grain diameters of the $\beta$ phase were determined by Jeffries procedure. ${ }^{10)}$ The mean grain diameter $(d)$, the relative grain size $(d / t)$ and $(d / w)$ normalized by thickness $(t)$ and width $(w)$ of the sheet specimen are listed in Table 1.

The martensitic transformation temperatures $\left(M_{s}, M_{f}, A_{s}\right.$ and $A_{f}$ ) of all the non-deformed specimens (listed in Table 1) and the deformed specimens were measured by differential scanning calorimetry (DSC) at heating and cooling rates of $10^{\circ} \mathrm{C} / \mathrm{min}$. The dimension of the specimens for DSC measurement was $3 \times 3 \times 0.5 \mathrm{~mm}^{3}$ for specimens $\mathrm{A}-\mathrm{H}$ and $\mathrm{Zn}$, and $1 \times 3 \times 0.5 \mathrm{~mm}^{3}$ for specimens I-K. The martensitic transformation temperatures of the deformed specimens were determined during the first cooling after heating up to $200^{\circ} \mathrm{C}$ and the second heating. They were defined as the temperatures at which differential DSC curve deviated from its base line due to the martensitic transformation as shown in Fig. 1.

The dimension of the specimens for TWME examination was $3 \times 50 \times 0.5 \mathrm{~mm}^{3}$ for specimens $\mathrm{A}-\mathrm{H}$ and $\mathrm{Zn}$, and $1 \times 50 \times 0.5 \mathrm{~mm}^{3}$ for specimens I-K. The TWME tests were performed by bending a sheet specimen into a round shape at room temperature followed by heating up to $200^{\circ} \mathrm{C}$. The degree of the TWME was determined by measurement of the curvatures at $-196^{\circ} \mathrm{C}$ and $200^{\circ} \mathrm{C}$. The TWME has been eval- 
Table 1 Nominal composition, grain diameter $d$, ratio of grain diameter to width of specimens $d / w$, ratio of grain diameter to thickness of specimens $d / t, M_{s}$ temperature of as-aged specimens and the maximum TWME $\varepsilon_{t w}$ in each alloy.

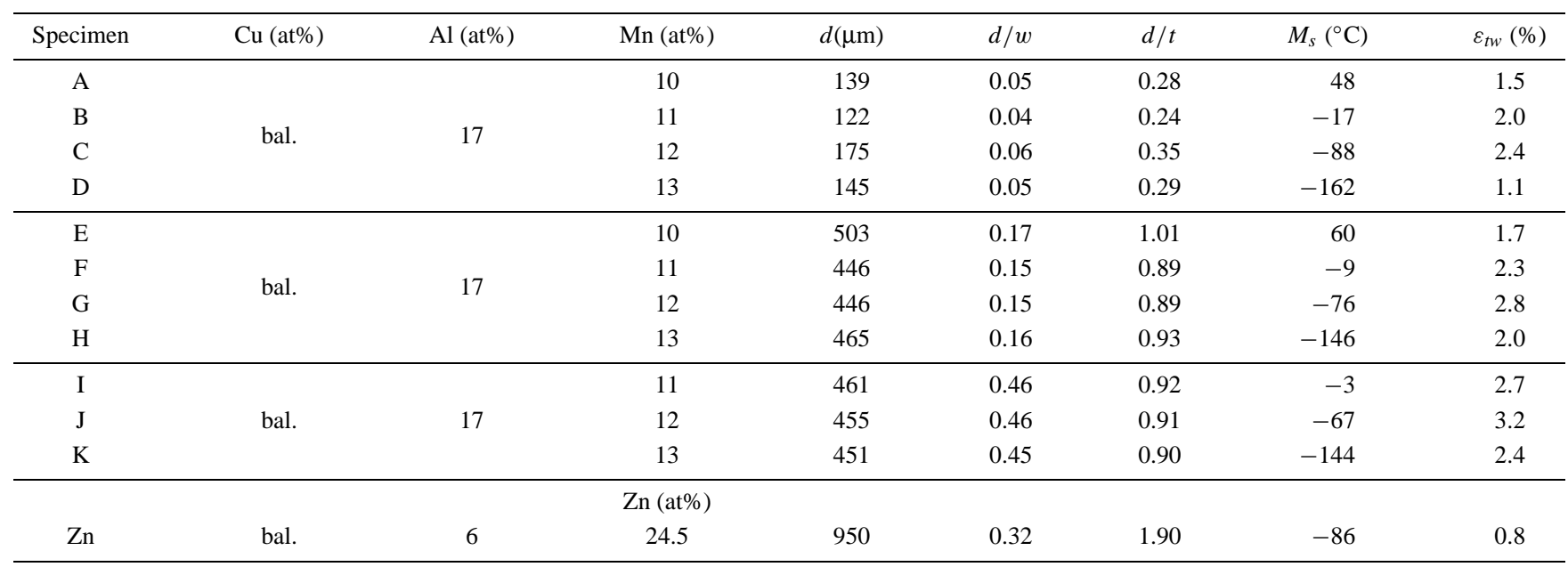

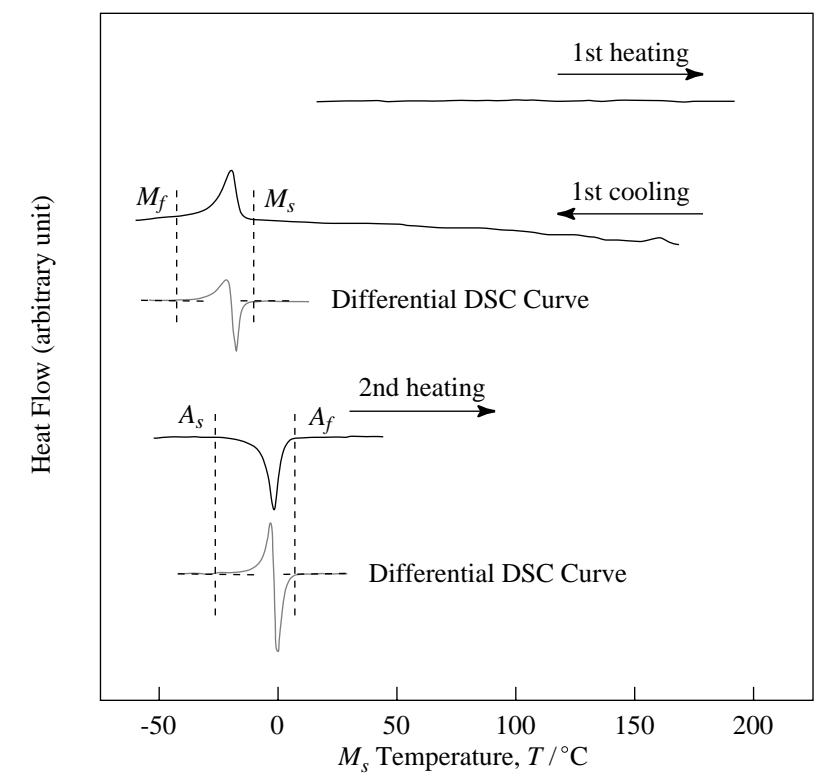

Fig. 1 A typical DSC curve of specimen B deformed up to $2.4 \%$. The definition of martensitic transformation temperatures is demonstrated.

uated by $\varepsilon_{t w}=\varepsilon_{c}-\varepsilon_{h}$, where $\varepsilon_{c}$ and $\varepsilon_{h}$ are the surface strains at $-196^{\circ} \mathrm{C}$ and $200^{\circ} \mathrm{C}$, respectively. The surface strain is defined as $\varepsilon=t / 2 r$, where $t$ is the thickness of the specimen and $r$ is the radius of curvature resulting from bending of the specimen.

In situ observation of a surface relief in the side surface of specimen $\mathrm{F}\left(3 \times 50 \times 0.5 \mathrm{~mm}^{3}\right)$ deformed up to $4.8 \%$ or $12.5 \%$ were performed during a cycle from $200^{\circ} \mathrm{C}$ to $-100^{\circ} \mathrm{C}$ using an optical microscope (OM) with a heating and cooling stage. The specimens for the observation were electrolytic polished in a solution of chromium oxide, acetic acid and water at a ratio of $25 \mathrm{~g}$ : $133 \mathrm{cc}$ : $7 \mathrm{cc}$ and etched in a solution of ferric chloride, hydrochloric acid and water at a ratio of $10 \mathrm{~g}$ : $25 \mathrm{cc}$ : $100 \mathrm{cc}$, followed by bending and unloading at room temperature.

\section{Results and Discussion}

\subsection{Transformation temperatures}

The transformation temperatures of specimens B and I are plotted against applied surface strain (ASS) in Fig. 2, where the $M_{s}$ and $A_{f}$ temperatures increase with increasing degree of pre-deformation, while the $A_{s}$ and $M_{f}$ temperatures decrease. The thermodynamic equilibrium temperatures $T_{0}$ and $T_{0}^{\prime}$, defined as $T_{0}=\left(M_{s}+A_{f}\right) / 2$ and $T_{0}^{\prime}=\left(M_{f}+A_{s}\right) / 2$, are also shown. It should be noted that while the transformation temperature hysteresis $(T T H), A_{f}-M_{s}$, is almost constant, the other $T T H, A_{s}-M_{f}$, clearly widens with increasing pre-deformation. On the other hand, the difference between $T_{0}$ and $T_{0}^{\prime}$ increases with increasing pre-deformation. From the thermodynamic point of view on thermoelastic martensite transformations, the TTHs and the transformation temperature intervals (TTIs : $M_{s}-M_{f}$ and $A_{f}-A_{s}$ ) are strongly related to the friction energy against the habit plane migration and to the elastic energy stored by growth of the martensite phase, respectively. ${ }^{11)}$ The present results suggest that the pre-deformation lowers the mobility of the habit plane at near $M_{f}$ and $A_{s}$ temperatures and enlarges the elastic energy.

It was reported that relative grain size $d / t$ normalized by the sheet thickness $t$ is one of the most important factors on the SM properties. ${ }^{12)}$ Very recently, the present authors have found that another relative grain size $d / w$ normalized by the sheet width $w$ should also be taken into account, and that the larger the $d / t$ and $d / w$, the smaller the constrained stresses. ${ }^{13)}$ In the present study, $d / w$ was used as a variable to express the relative grain size. The martensitic transformation temperatures are affected by the change of the $d / w$ as shown in Fig. 2, where the TTHs and TTIs are larger in the specimen of $d / w=0.04$ than those in the specimen of $d / w=0.46$. This result can also be explained as follows: The constrained stress from the surrounding neighboring grains causes the increase of friction and elastic energies.

\subsection{Two-way shape memory properties}

Figure 3 shows the result of the TWME induced by bending deformation as a function of ASS in the $\mathrm{Cu}_{83-X} \mathrm{Al}_{17} \mathrm{Mn}_{X}$ 
(a) $d / w=0.04$ (specimen B)

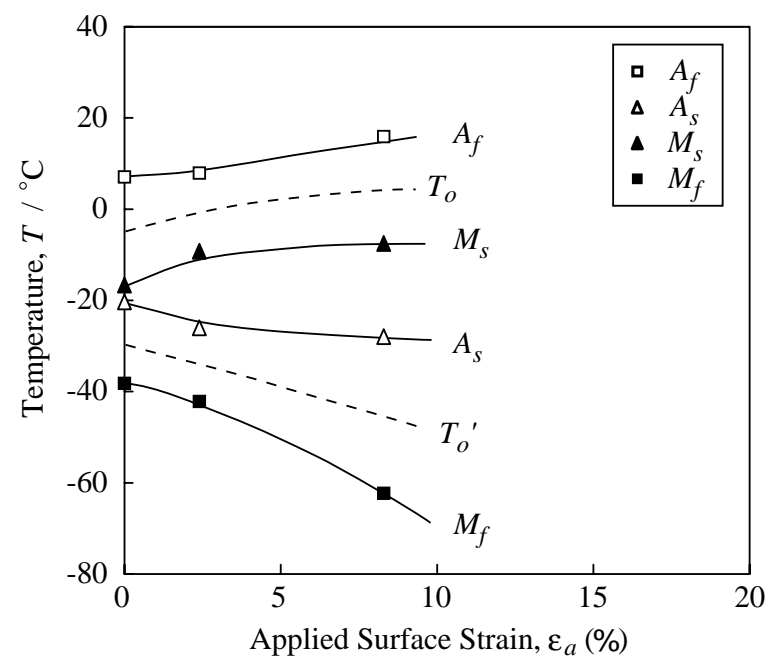

(b) $d / w=0.46$ (specimen I)

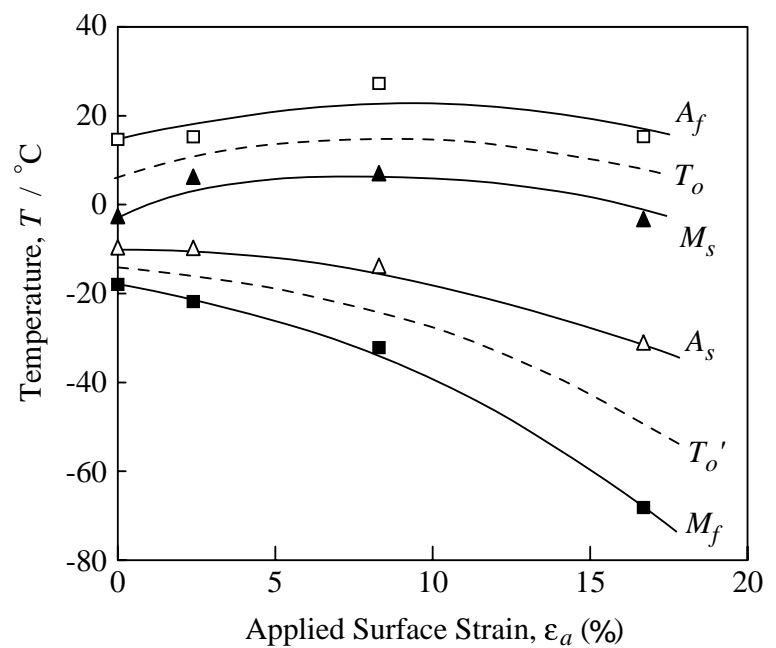

Fig. 2 The change of martensitic transformation temperatures of specimens $B$ and I after bending followed by unloading and subsequent heating up to $200^{\circ} \mathrm{C}$

$(X=10,11,12,13)$ and $\mathrm{Cu}-\mathrm{Zn}-\mathrm{Al}$ alloys for comparison. In all the cases, the TWME increases with increasing the ASS in the early stage and then decreases after reaching at a maximum point. This fact suggests that an appropriate density of slip defects is effective for improvement of TWME and excessive density of them reduces the TWME. An excellent value of TWME $=2.8 \%$ was obtained in the specimen of $\mathrm{Cu}_{71} \mathrm{Al}_{17} \mathrm{Mn}_{12}$ deformed up to $12.5 \%$, where the ratio of TWME to ASS was about $22 \%$. The details on the effect of $M_{s}$ temperature and ASS on TWME are discussed in our previous papers. ${ }^{14,15)}$

The effect of the relative grain size $d / w$ on TWME of the $\mathrm{Cu}_{72} \mathrm{Al}_{17} \mathrm{Mn}_{11}$ alloy is shown in Fig. 4. The specimens with larger $d / w$ exhibit the maximum point at the higher ASS. Since the SME and SE of the $\mathrm{Cu}-\mathrm{Al}-\mathrm{Mn}$ alloys decrease with decreasing the $d / w$ and the specimens with smaller $d / w$ start to show an irrecoverable strain in the lower ASS level, ${ }^{13,16,17)}$ it may be reasonable that the degree of the ASS to obtain the

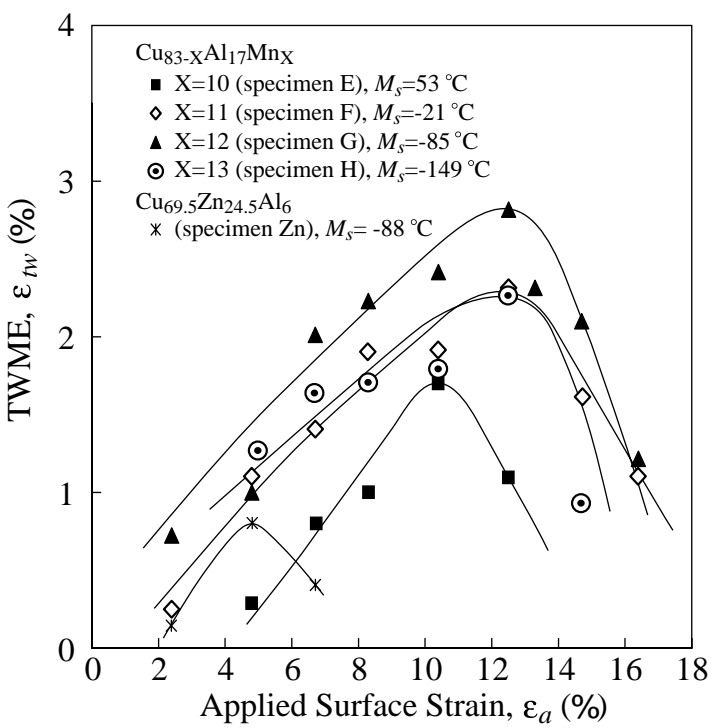

Fig. 3 The TWME induced by bending deformation is plotted as a function of applied surface strain in specimens E, F, G, H and Zn.

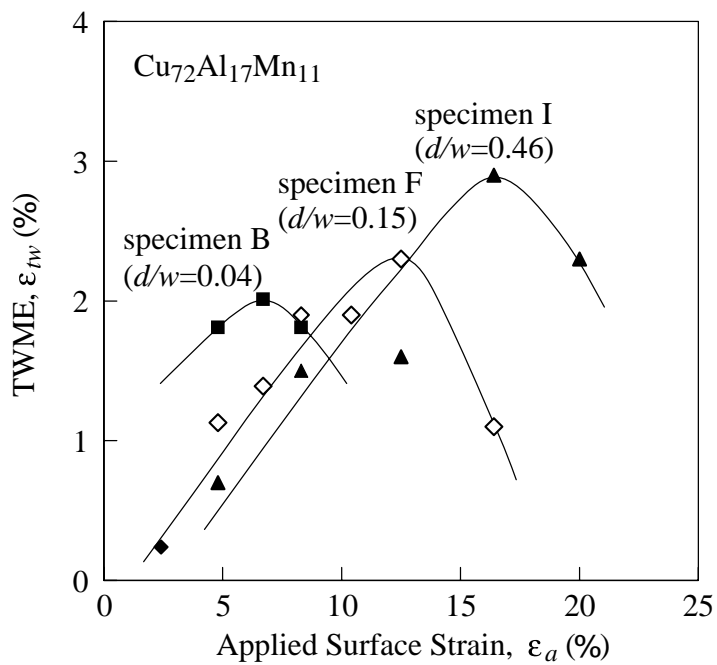

Fig. 4 The effect of grain size on the TWME in specimens B, F and I. The $d / w$ is the ratio of the grain diameter to the width of the specimens.

density of the slip defects appropriate for TWME decreases with decreasing the $d / w$. Therefore, the TWME decrease in the lower ASS level, which leads to the small TWME in such specimens with small $d / w$.

Figure 5 shows the variation of the maximum values of the TWME with the $M_{s}$ temperature in all the $\mathrm{Cu}-\mathrm{Al}-\mathrm{Mn}$ specimens, where the maximum TWME increases with decreasing $M_{s}$ temperature up to $M_{s}=-100^{\circ} \mathrm{C}$ and then decreases in all the series of the $d / w$. This result means that an excellent TWME can be obtained in specimens with $M_{s}$ temperature of about $120^{\circ} \mathrm{C}$ lower than the deformation temperature. The relationship between the critical stress for transformation $\sigma_{t}$ and the deformation temperature is described by the Clausius-Clapeyron type relationship. ${ }^{18)}$ The present authors recently determined their relationship in the $\mathrm{Cu}-\mathrm{Al}-\mathrm{Mn}$ alloys with $d / w=0.06$ and $d / t=1$ as shown in Fig. $6{ }^{13,17)}$ The stresses for $\sigma_{t}$ and the critical slip stress ${ }^{19)} \sigma_{s}$ are illustrated in Fig. 7, where the $\sigma_{s}$ is defined in this paper as the stress over which the residual strain of $0.2 \%$ is introduced in 


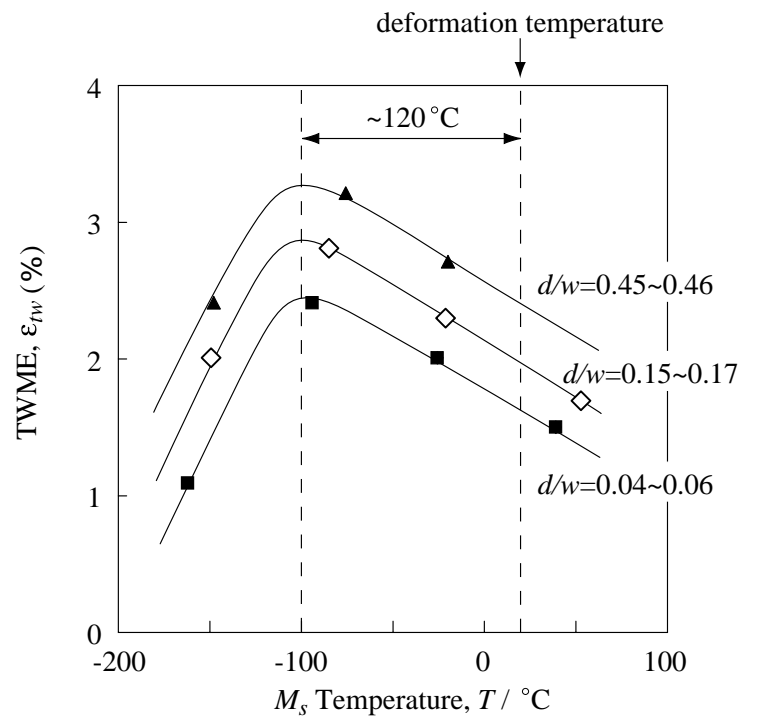

Fig. 5 The TWME in the $\mathrm{Cu}-\mathrm{Al}-\mathrm{Mn}$ alloys as a function of the $M_{s}$ temperature.

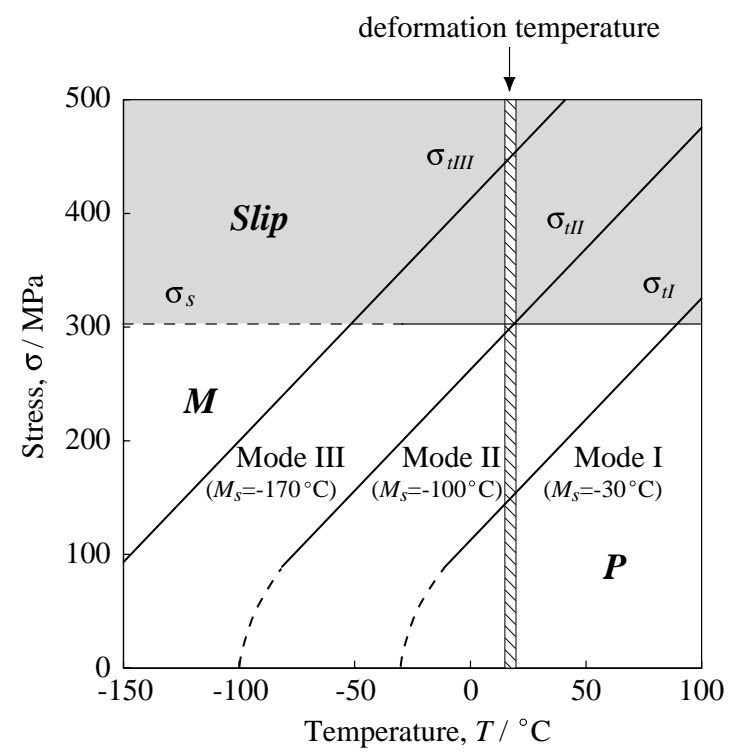

Fig. 6 The relation between the critical stress for transformation and the deformation temperature. The introduction of slip defects can be classified into three modes.

the SE tensile tests at the deformation temperatures. $\sigma_{s}$ is evaluated from the stress-strain curve of the $\mathrm{Cu}_{72} \mathrm{Al}_{17} \mathrm{Mn}_{11}$ polycrystalline alloys, and no apparent dependence of $\sigma_{s}$ on temperature was observed within the temperature range of the tests. The introduction of slip defects can be classified into three modes as demonstrated in Fig. 6:

(Mode I) $\sigma_{s}>\sigma_{t}$ at room temperature at which the bending test was made in the present study. Slip defects are introduced into the full martensite phase.

(Mode II) $\sigma_{s} \approx \sigma_{t}$ at room temperature. It may be possible that slip defects are yielded in both the parent and martensite phases. The dislocations, however, may be expected to be concentrated in the vicinity of the habit plane.

(Mode III) $\sigma_{s}<\sigma_{t}$ at room temperature. Slip defects are introduced into the parent phase.

Under the deformation at room temperature, the alloys with

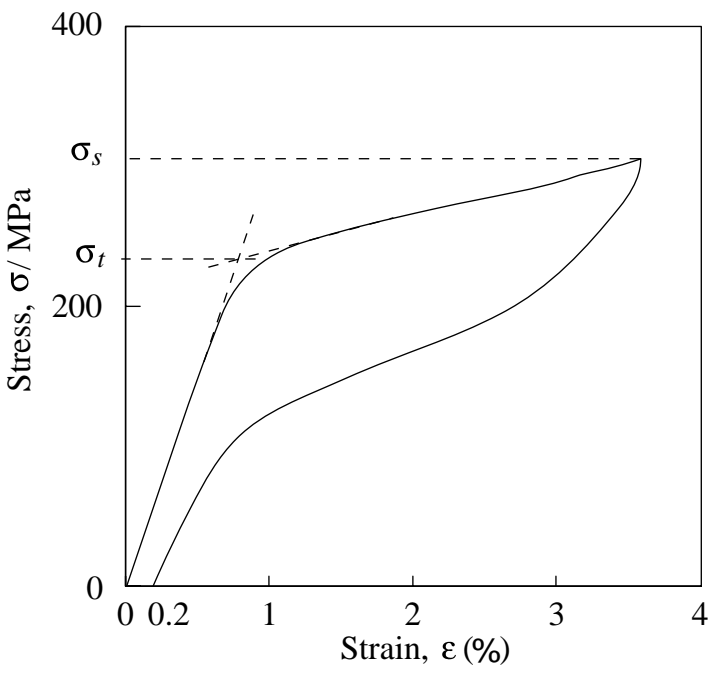

Fig. 7 A stress-strain curve obtained by tensile test at $50^{\circ} \mathrm{C}$ in $\mathrm{Cu}_{72} \mathrm{Al}_{17} \mathrm{Mn}_{11}$ alloy with $d / w=0.06$ and $d / t=1$.

$M_{s} \approx-100^{\circ} \mathrm{C}$ which show the maximum TWME in Fig. 5 correspond to Mode II. This fact suggests that the slip defects introduced under conditions of coexistence with the parent and martensite phases play an important role in the excellent TWME.

As shown in Fig. 5, a high degree of TWME was obtained in the specimens with a large $d / w$. The value of TWME (3.2\%) obtained in the specimen $\mathrm{J}$ with $M_{s}\left(-67^{\circ} \mathrm{C}\right)$ and $d / w$ (0.46) shows the highest magnitude of the TWME in $\mathrm{Cu}$-base SM alloys.

\subsection{In situ observation of surface relief}

The microstructural changes of a side surface in the specimen $\mathrm{F}\left(M_{s}=-9^{\circ} \mathrm{C}\right)$ pre-deformed to an ASS of $4.8 \%$ and $12.5 \%$ (whose TWMEs were about $1.1 \%$ and $2.3 \%$, respectively) during heating and cooling are shown in Figs. 8 and 9, respectively. Although the $M_{s}$ temperature of the specimen $\mathrm{F}$ in Figs. 8 and 9 determined by DSC is $-7^{\circ} \mathrm{C}$ and $-4^{\circ} \mathrm{C}$, respectively, a lot of martensite plates are observed in all the microphotographs taken at $25^{\circ} \mathrm{C}$ cooled down from $200^{\circ} \mathrm{C}$. This fact suggests that the DSC measurement is detectable to only the transformation of the main part of the specimen.

In the heating process (a) to (c), no remarkable differences were observed between Figs. 8 and 9 except for the amount of the retained martensite plates. Many stress-induced martensite plates remain near both the upper and lower surfaces at $25^{\circ} \mathrm{C}$ after unloading. As shown by the arrows in (a) to (c), while the martensite plates continuously shrink and disappear with increasing temperature, some martensite plates still exist even at $200^{\circ} \mathrm{C}$.

On the other hand, the cooling process (d) to (f) shows an interesting feature in microstructural changes between Figs. 8 and 9. The martensite plates observed at $200^{\circ} \mathrm{C}$ grow to the center of the specimen with decreasing temperature, and only the specific plates appear during cooling as shown in both Figs. 8(d) and 9(d). Upon further cooling (e) to (f), the typical microstructure showing self-accommodation appears only in Fig. 8. In Fig. 9(e), there is a tendency that the thickness of the growing martensite plates hardly increases and many new 

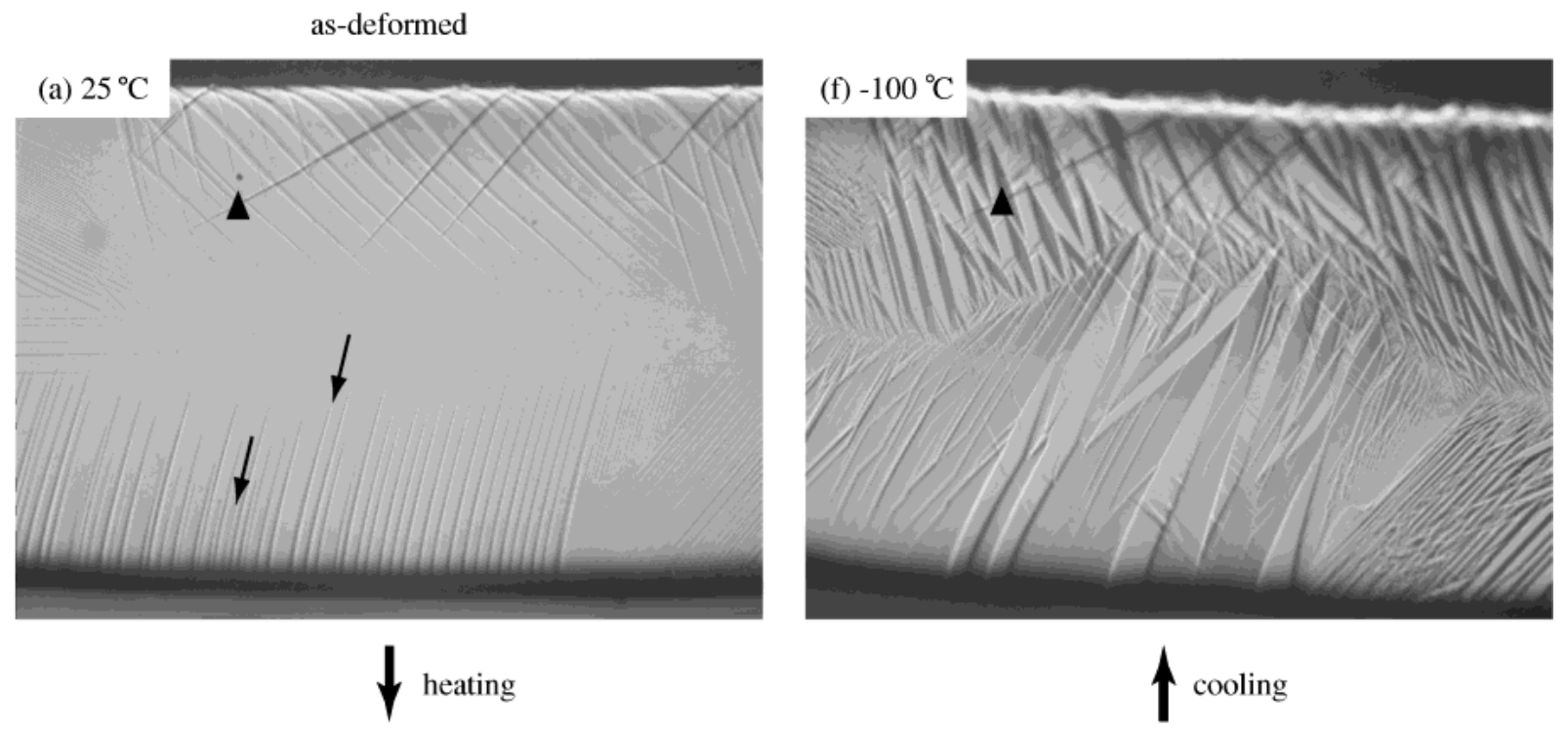

(b) $100{ }^{\circ} \mathrm{C}$
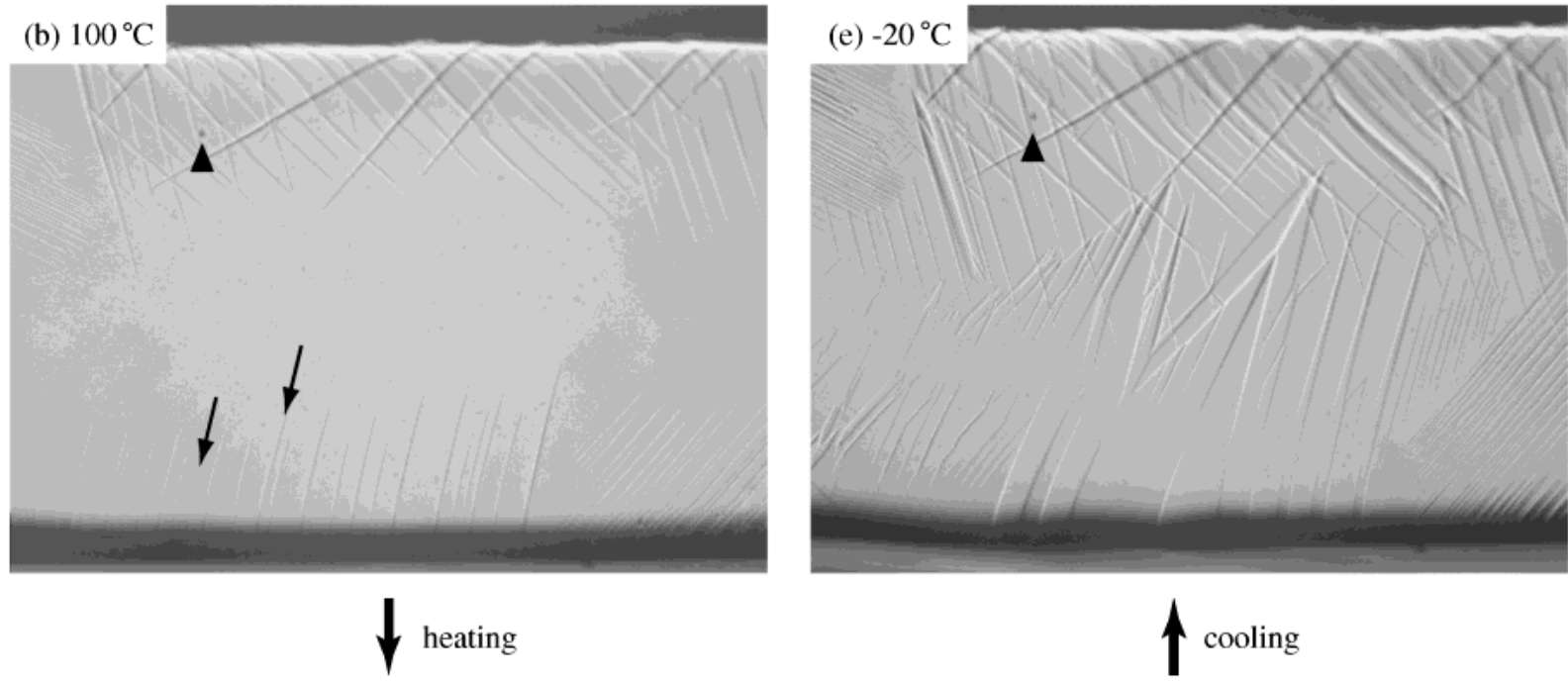

(c) $200{ }^{\circ} \mathrm{C}$

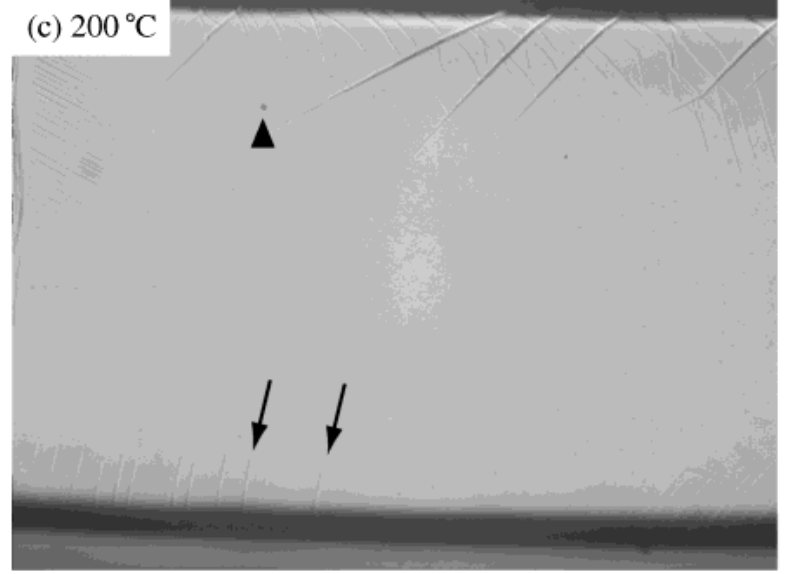

(d) $25^{\circ} \mathrm{C}$

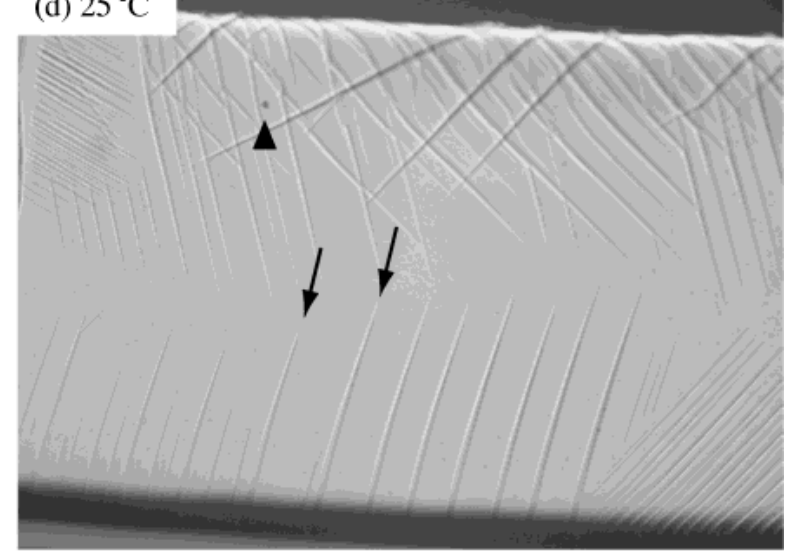

$\overrightarrow{\text { cooling }}$

Fig. 8 The OM observation of side surface of specimen $\mathrm{F}$ during heating to $200^{\circ} \mathrm{C}$ and subsequent cooling to $-100^{\circ} \mathrm{C}$. The specimen was bent to an ASS of $4.8 \%$ and unloaded.

martensite plates are formed between the retained martensite plates. Consequently, the microstructure at $-100^{\circ} \mathrm{C}$ shows a high density of the martensite plates, with the thickness of only some of the plates increasing.

\subsection{TWME and TTH}

According to the in situ observation of the surface relief of the $12.5 \%$ pre-deformed specimen with an excellent TWME, the martensite phase with a specific variant is formed and no self-accommodation is clearly observed. It is clear that these 
as-deformed

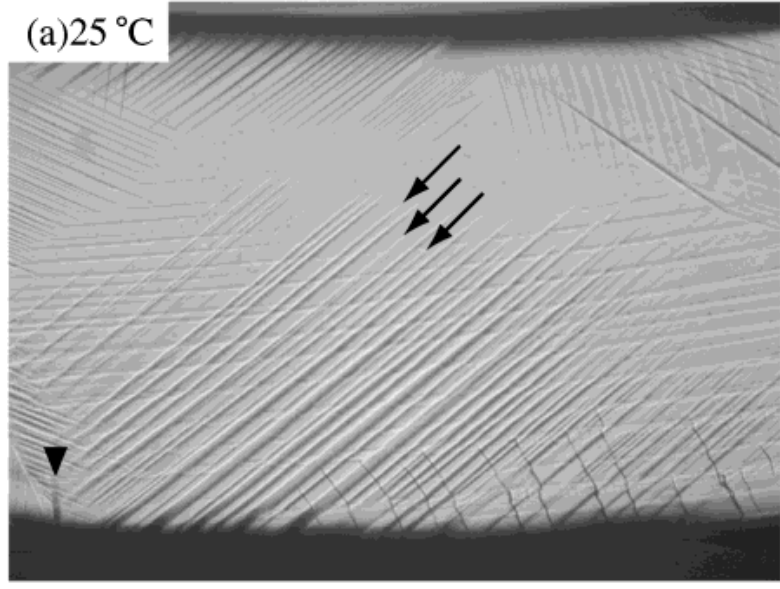

$\downarrow$ heating

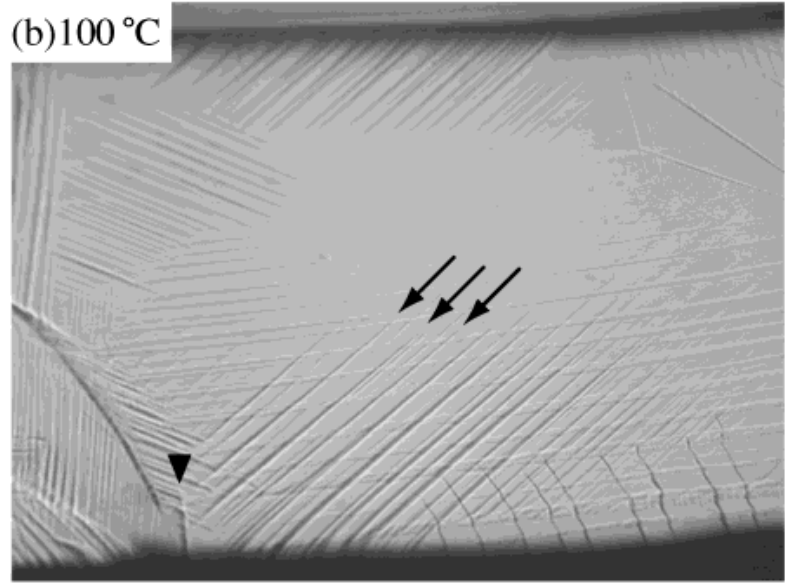

$\downarrow$ heating

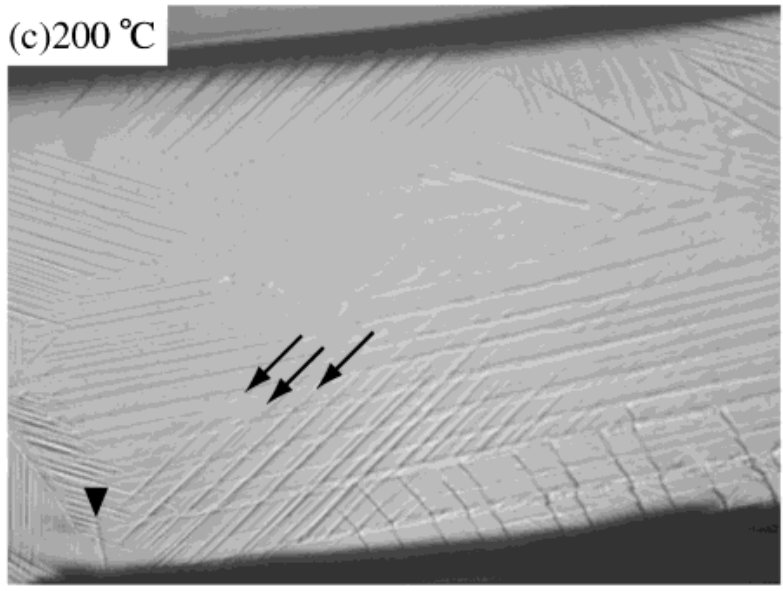

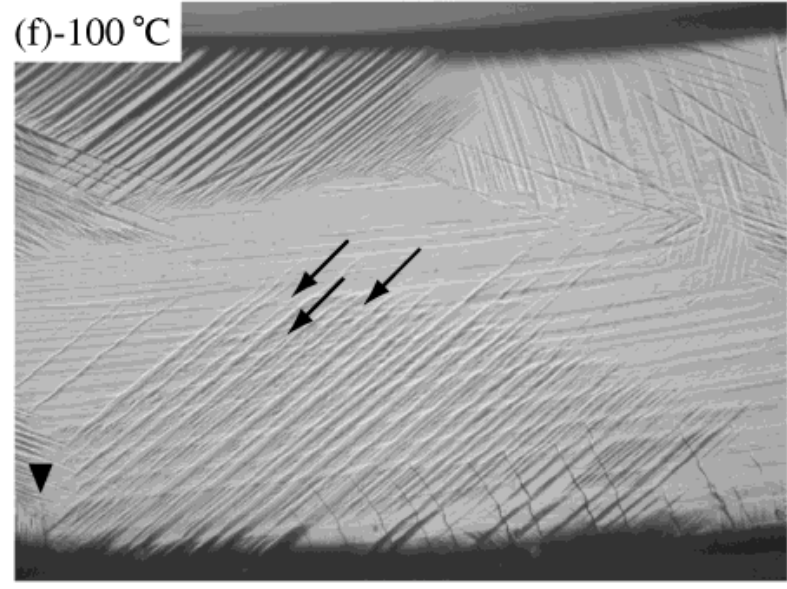

^ cooling

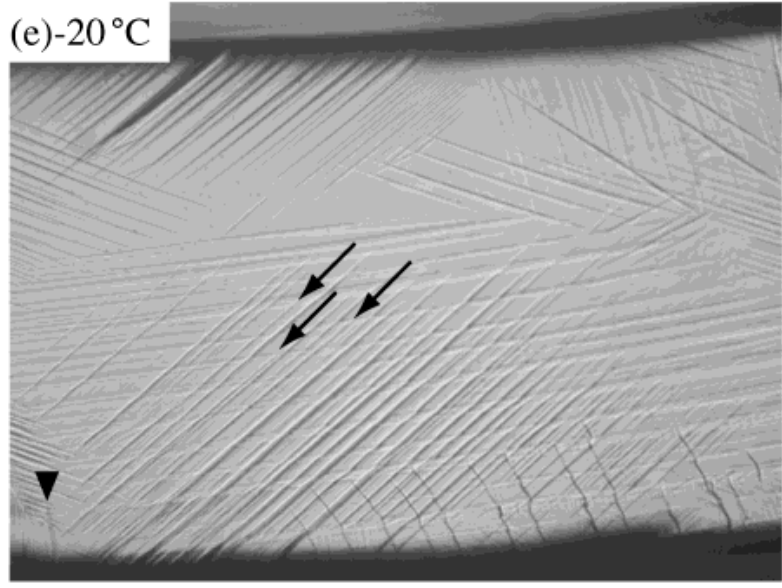

^ cooling

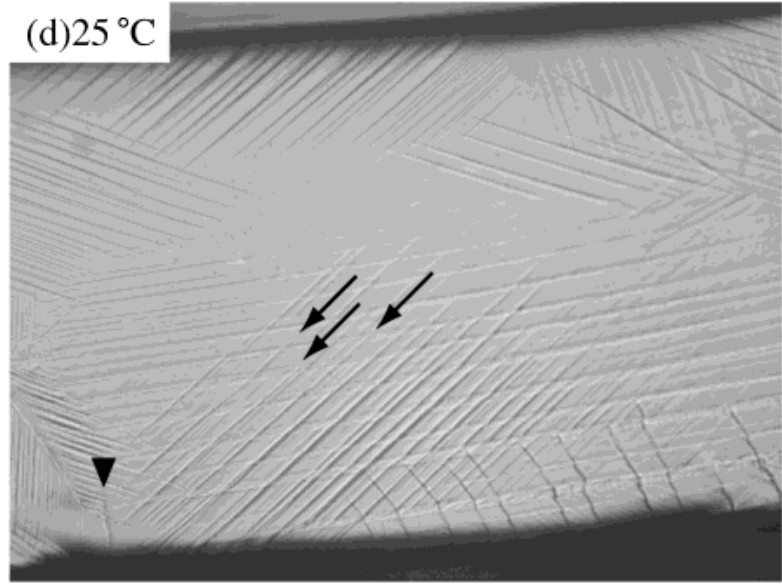

$\rightarrow$

Fig. 9 The OM observation of the side surface of specimen F, where the ASS was $12.5 \%$.

characteristic features play a key role in the improvement of the TWME. Such restriction of variants may be explained by the introduction of dislocation arrays. It was reported that the dislocations in bands parallel to the parent/martensite habit plane are observed at $-100^{\circ} \mathrm{C}$ and this type of dislocations become dominant at higher temperatures in superelastically cycled $\mathrm{Cu}-\mathrm{Zn}-\mathrm{Al}$ alloys. ${ }^{20)}$ The accumulation of such kind of dislocations is explained as the result due to the inter- 
(a)

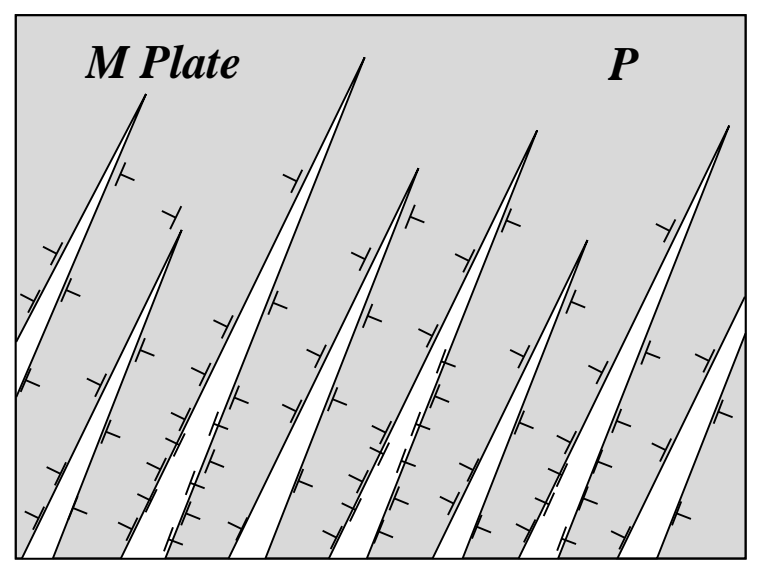

(b)

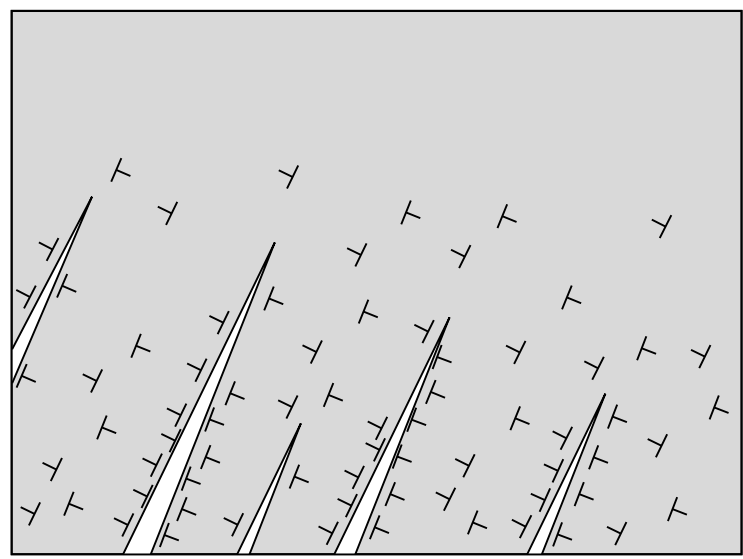

(c)

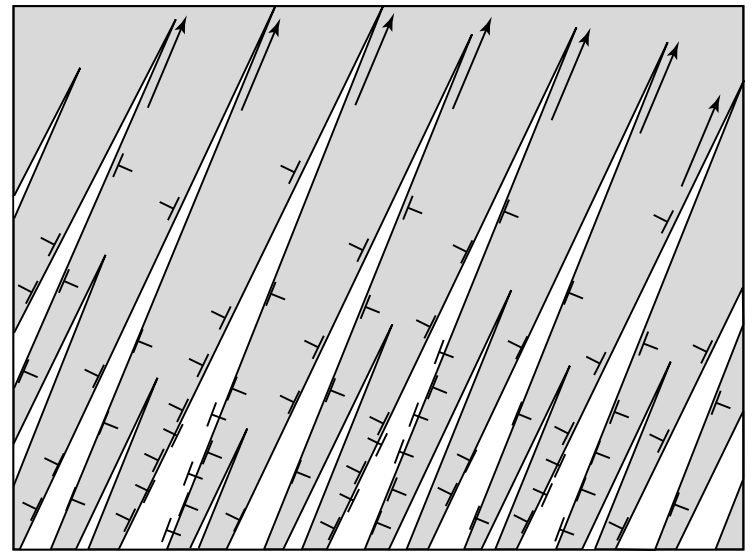

(d)

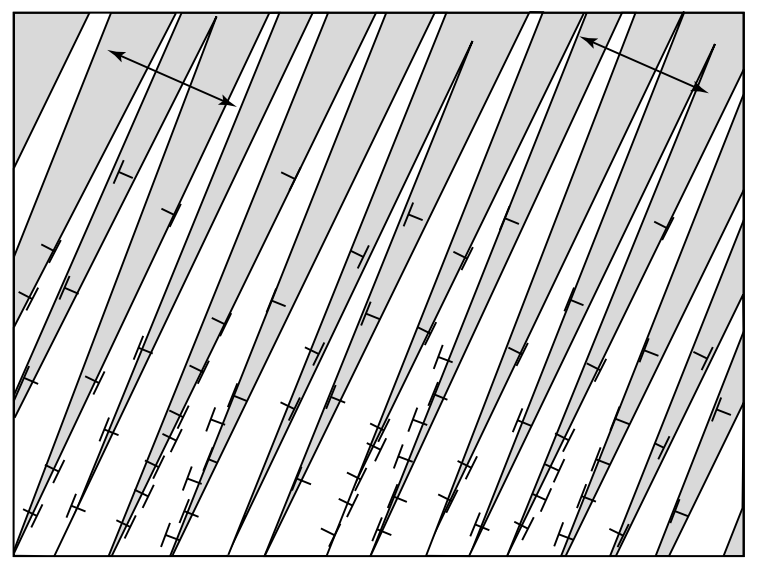

Fig. 10 A schematic illustration of martensite growth by cooling, where dislocations are introduced by bending deformation. (a) after bending deformation, (b) heating up to $200^{\circ} \mathrm{C}$, (c) cooling and (d) further cooling.

nal stresses between the parent and martensite phases arising from the shape strain by transformation..$^{20,21)}$ If the dislocations should exist in the vicinity of the parent/martensite phase boundaries as schematically illustrated in Fig. 10, it seems that the growth of each martensite plate in the direction of width is difficult in contrast with that in directions of length of the martensite plate. Therefore, a new variant parallel to the previous plates may tend to appear instead of growth of the martensite plate. It is easily expected from Fig. 10 that the mobility of the habit plane is lost and that the TTH $\left(A_{s}-M_{f}\right)$ increases with increasing dislocation density. The value of the other $T T H$, i.e., $A_{f}-M_{s}$, may be mainly concerned with the transformation in the central region of the bent specimen in which strain is relatively small, resulting in the lack of dependence on the ASS as shown in Fig. 2.

\section{Conclusions}

(1) The $M_{s}$ and $A_{f}$ temperatures increase with increasing degree of pre-deformation, while the $M_{f}$ and $A_{s}$ temperatures decrease.

(2) The TWME is a function of the degree of predeformation and reaches its highest value at the specific degree which is dependent on the relative average grain size $d / w$ of the specimens.
(3) A high level of TWME was obtained in the specimens with an $M_{s}$ temperature of about $-100^{\circ} \mathrm{C}$. The larger the $d / w$ was, the higher the TWME obtained, and $3.2 \%$ of TWME was obtained in the specimen with $M_{s}=-67^{\circ} \mathrm{C}$ and $d / w=0.46$.

(4) In situ observations of the surface relief clarified that some martensite plates with specific variants stress-induced by the $12.5 \%$ pre-deformation are stabilized and present even at $200^{\circ} \mathrm{C}$, and these martensite plates and some new martensite plates parallel to the previous plates grow from the surface to the center region with decreasing temperature without selfaccommodation. The excellent TWME in the present study is explained by this characteristic change in the microstructure.

\section{Acknowledgements}

This work was supported by Grant-in-Aids for Scientific Research from the Ministry of Education, Science, Sports and Culture, Japan.

\section{REFERENCES}

1) R. Kainuma, N. Satoh, X. J. Liu, I. Ohnuma and K. Ishida: J. Alloys Comp. 266 (1998) 191-200.

2) R. Kainuma, S. Takahashi and K. Ishida: Metall. Mater. Trans. A 27A (1996) 2187-2195.

3) R. Kainuma, S. Takahashi and K. Ishida: J. de Phys. IV 5 C8 (1995) 
961-966.

4) J. Perkins and R. O. Sponholz: Metall. Trans. A 15A (1984) 313-321.

5) D. Rios-Jara and G. Guenin: Acta Metall. 35 (1987) 109-119.

6) R. Stalmans, J. Van Humbeeck and L. Delaey: Acta Metall. Mater. 40 (1992) 2921-2931.

7) E. Cingolani, M. Ahlers and M. Sade: Acta Metall. Mater. 43 (1995) 2451-2461.

8) A. Nagasawa, K. Enami, Y. Ishino, Y. Abe and S. Nenno: Scr. Metall. 8 (1974) 1055-1060.

9) K. Takazawa and S. Sato: Proc. Int. Symp. on New Aspects of Martensitic Transformation, Supplement to Trans. JIM 17 (1976) 233-238.

10) F. Schückher: Quantitative Microscopy, ed. by R. T. DeHoff and F. N. Rhines, (McGraw-Hill Book Company, New York, 1968) pp. 239.

11) P. Wollants, J. R. Roos and L. Delaey: Prog. Mater. Sci. 37 (1993) $227-$ 288.

12) I. Dvorak and E. B. Hawbolt: Metall. Trans. A 6A (1975) 95-99.
13) Y. Sutou: Doctoral Thesis, Tohoku University (2001).

14) T. Omori, J. J. Wang, Y. Sutou, R. Kainuma and K. Ishida: Proc. of Fourth Pacific Rim International Conference on Advanced Materials and Processing (2001) 1887-1890.

15) T. Omori, Y. Sutou, T. Okamoto, R. Kainuma and K. Ishida: Trans. Mater. Res. Soc. Jpn. 26[1] (2001) 227-230.

16) Y. Sutou, T. Omori, T. Okamoto, R. Kainuma and K. Ishida: J. de Phys. IV 11 Pr8 (2001) 185-190.

17) Y. Sutou, T. Omori, J. J. Wang, R. Kainuma and K. Ishida: submitted to ICOMAT '02.

18) P. Wollants, M. De Bonte and J. R. Roos: Z. Metallkd. 70 (1979) 113117.

19) K. Otsuka and K. Shimizu: Int. Metals Rev. 31 No. 3 (1986) 93-114.

20) J. Malarria, M. Sade and F. Lovey: Mater. Sci. Eng. A 308 (2001) 88100.

21) K. Marukawa and S. Kajiwara: Philos. Mag. A 55 (1987) 85-97. 